\title{
Estudo da produção de sinter feed e pellet feed de acordo com a granulometria
}

\section{Study of sinter feed and pellet feed production according to the granulometry}

Aline da Luz Pascoal, Filipe Mattos Gonçalves, Manuella dos Anjos Andrade, Ana Paula Aparecida de Almeida Paulo, Júnia Soares Alexandrino

\section{RESUMO}

A produção de finos de minério de ferro atualmente necessita de uma maior recuperação, sendo esta relacionada aos baixos teores de $\mathrm{Fe}$ referentes à escassez das jazidas e também intrínsecas à crescente demanda das indústrias siderúrgicas quanto a adequados teores de Fe, granulometria e de desempenho metalúrgico nos altos fornos. De maneira que, o objetivo deste trabalho foi o estudo da produção de pellet feed e sinter feed embasando-se somente na granulometria requerida para cada um desses produtos, que é uma variável muito importante dos concentrados, pois para a alimentação dos fornos de redução os concentrados com granulometrias inferiores têm necessariamente que passar por um processo de aglomeração. Sendo assim, a realização dos ensaios de bancada: britagem, moagem e classificação, foram indispensáveis para uma melhor investigação do circuito de concentração do minério de ferro itabirítico de aproximadamente 30,0 a 50,0 mm - lump, voltados para a produção de finos e ultrafinos. Os fatores impactantes correlacionados à produção de pellet feed e sinter feed são listados como sendo, a cominuição, a variação da massa de alimentação, a variação do diâmetro de abertura do gap do britador e moinho. Ensaios de peneiramento, de densidade e umidade do minério foram realizados para caracterizar o minério itabirítico.

Palavras- chave: Cominuição; Granulometria; Minério de Ferro.

\begin{abstract}
The production of fine iron ore currently requires a greater recovery, which is related to low levels of iron due to the scarcity of deposits and also the intrinsic growing demand from the steel industry for appropriate Fe content, particle size and metallurgical performance in blast furnaces. So that, the objective of this work was to study the production of pellet feed and sinter feed basing solely on the particle size required for each of these products, which is a very important variable of the concentrates, as to feed the reduction furnaces the concentrated with lower grain sizes has necessarily to go through an agglomeration process. Thus, the performance of bench tests: crushing, grinding and classification were indispensable for further investigation about the concentration circuit of itabiritic iron with approximately 30,0 to $50.0 \mathrm{~mm}$ - lump, focused on the production of fine and ultrafine particles. The impacting factors related to the production of pellet feed and sinter feed are listed as comminution, the variation of the feed mass, the gap opening variation of the crusher and mill. Sieving, density and moisture tests were performed to characterize the itabiritic ore.
\end{abstract}

Keywords: Comminution; Granulometry; Iron ore. 


\section{INTRODUÇÃO}

O minério de ferro é a matéria-prima básica para a siderurgia, pois responde pelas unidades metálicas $(\mathrm{Fe})$ que promovem a alimentação do alto forno e dos fornos elétricos. De acordo com Bennett ${ }^{(1)}$, a qualidade do minério de ferro está basicamente ligada a três características: química, que corresponde à própria composição (quanto maior o teor de ferro e menor o de impurezas melhor): física, que se refere à granulometria, ou seja, ao tamanho das partículas; metalúrgica (itens de desempenho que afetam a produtividade durante o processo siderúrgico). Isso requer alto nível de controle nas etapas de cominuição, peneiramento e classificação, mesmo para minérios de alto teor de ferro e baixo nível de impurezas, atendendo, assim, às exigências do mercado.

Quaresma $^{(2)}$ e Jesus $^{(3)}$ afirmam que a utilização do minério é feita normalmente de duas formas: minérios granulados e minérios aglomerados. Os granulados entre $(25,0 \mathrm{~mm}$ e 6,00 $\mathrm{mm})$ são adicionados nos fornos de redução, enquanto os aglomerados são os minérios finos, que devido à sua granulometria necessitam de uniformização. Os principais processos de aglomeração são a sinterização e a pelotização, indicados respectivamente, para minérios de granulometria entre $6,00 \mathrm{~mm}$ e $0,150 \mathrm{~mm}$ (sinter feed) e menores que $0,150 \mathrm{~mm}$ (pellet feed).

Neste sentindo, o material deve ser primeiro reduzido de tamanho (fragmentação) e classificado quanto à granulometria, etapas fundamentais e constituintes do tratamento de minérios ${ }^{(4)}$. Assim, a realização do peneiramento apresenta como objetivo a separação de certo material em duas ou mais frações, com partículas de tamanhos distintos, para que posteriormente se execute a sua classificação. Usa-se a simbologia (+) para designar que o material ficou retido na peneira e (-) para o material que passou da mesma, de maneira que para determinar as faixas de tamanho das partículas, é realizada a montagem de uma sequência de peneiras com aberturas estipuladas, conhecida como malhas.

O peneiramento pode ser realizado tanto a seco, sendo este utilizado em faixas granulométricas mais grosseiras, como também a úmido, adicionando-se água ao material no momento do peneiramento para facilitar a passagem dos finos através da tela da peneira.

\section{MATERIAIS E MÉTODOS}

O ensaio de fragmentação e classificação do ROM de um minério itabirítico (Fig. 1) com massa de $10000 \mathrm{~g}$ foi realizado em um circuito de britagem e moagem em bancada, onde se executou inicialmente a conferência e o ajuste do gap do britador de mandíbulas (CDC - Modelo 120080, Série BM 21), para redução do minério de ferro de top size de 50,0 $\mathrm{mm}$ do ROM para um top size de 4,15 mm para otimização da carga circulante.

Dessa forma, foi realizado o escalpe e posteriormente a classificação da amostra utilizando o conjunto de peneiras granulométricas quadradas $(6,30 \mathrm{~mm} ; 0,150 \mathrm{~mm})$, em um tempo de 3 minutos para o escalpe e 5 minutos para a classificação. $\mathrm{Na}$ realização do ensaio foi utilizado um peneirador quadrado, com o objetivo de se produzir sinter feed e pellet feed, somente quanto à classificação granulométrica, como está discriminado na Tabela 1.

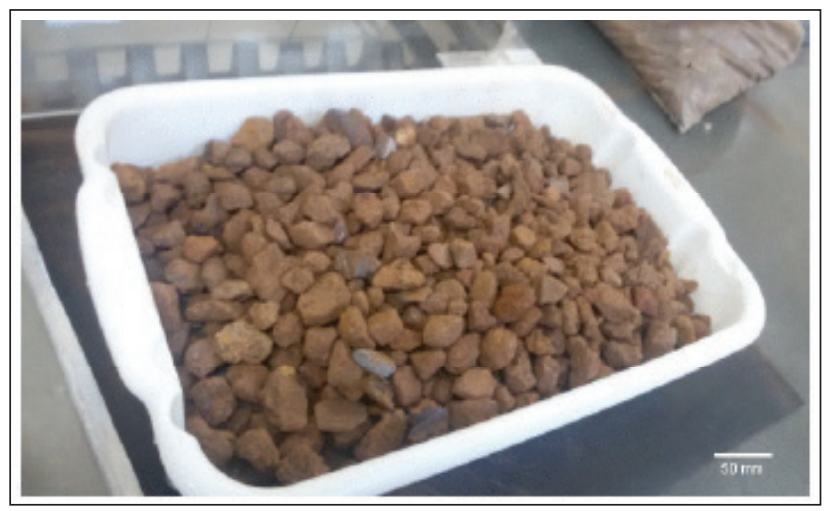

Figura 1: Amostra de minério itabirítico - lump

Tabela 1: Produtos de minério de ferro

\begin{tabular}{|c|c|}
\hline Sinter feed & Limite (\%) \\
\hline$+6,35 \mathrm{~mm}$ & 10 \\
$-0,150 \mathrm{~mm}$ & 42 \\
\hline Pellet feed & Limite (\%) \\
$+0,150 \mathrm{~mm}$ & 5 \\
$-0,044 \mathrm{~mm}$ & $80-90$ \\
\hline
\end{tabular}

Fonte: Lima(5)

Com a realização da classificação, o material $(+6,30 \mathrm{~mm})$ foi considerado como carga circulante da britagem, já o material retido na faixa intermediária $(-6,30+0,150 \mathrm{~mm})$ foi considerado como carga circulante do moinho (sinter feed). E finalmente o material $(-0,150 \mathrm{~mm})$ foi o produto do processo (pellet feed).

Portanto, a carga circulante do moinho, a fração $(-6,30 \mathrm{~mm}+$ $0,150 \mathrm{~mm}$ ) foi obtida com massa de $3000 \mathrm{~g}$, sendo posteriormente encaminhada ao moinho de disco (CDC - Modelo MD-200, Série $\mathrm{MD})$. Todavia realizou-se antes a conferência e o ajuste do gap do moinho de disco, para a obtenção de frações mais finas, e para que assim, houvesse uma maior produção de pellet feed, todavia todo o procedimento de produção dos finos foi realizado em uma batelada.

Após o procedimento de moagem, foi executado o ensaio de peneiramento para classificação dos produtos em peneiras granulométricas $(6,30 \mathrm{~mm}$ e $0,150 \mathrm{~mm})$. De maneira que todo material retido na faixa $(-6,30+0,150 \mathrm{~mm})$ foi homogeneizado e quarteado, retirando uma alíquota de 163,6 g para análise granulométrica, em peneiramento a seco, visando à determinação da proporção do minério que já se encontrava nesta fração (sinter feed). Da mesma forma, o material proveniente da fração $(-0,150 \mathrm{~mm})$, também foi homogeneizado e quarteado, retirando uma alíquota de 95,0 g para análise granulométrica, em peneiramento a úmido, visando à determinação da proporção do minério que já se encontrava nesta fração (pellet feed). 
Assim, para o procedimento de peneiramento a seco (20 min), foi utilizada uma sequência de peneiras granulométricas redondas da série Tyler com as seguintes malhas $(4,75 \mathrm{~mm}$; $3,50 \mathrm{~mm} ; 2,40 \mathrm{~mm} ; 1,18 \mathrm{~mm} ; 0,850 \mathrm{~mm} ; 0,600 \mathrm{~mm} ; 0,425 \mathrm{~mm}$; $0,300 \mathrm{~mm} ; 0,180 \mathrm{~mm} ; 0,150 \mathrm{~mm}$ ) e para o peneiramento a úmido foi utilizada a série Tyler de peneiras granulométricas redondas $(0,150 \mathrm{~mm} ; 0,106 \mathrm{~mm} ; 0,075 \mathrm{~mm} ; 0,0053 \mathrm{~mm} ; 0,0045 \mathrm{~mm}$; $0,0038 \mathrm{~mm})$.

Contudo, para que a análise granulométrica seja possível é preciso que as peneiras retenham uma massa menor do que aquela estimada pela fórmula de Gaudin ${ }^{(6)}$ (Eq. 1), assegurando que todas as partículas terão a mesma chance de serem testadas na malha de abertura.

$\left.\mathrm{M}=\left[\left(\mathrm{d}_{\mathrm{i}}+\mathrm{d}_{\mathrm{s}}\right) / 2\right)\right] \times \rho \times A \times n$

$\mathrm{M}$ = Massa máxima retida em cada peneira $(\mathrm{g})$.

$\mathrm{d}_{\mathrm{i}}=$ Abertura da peneira em questão $(\mathrm{cm})$.

$\mathrm{d}_{\mathrm{s}}=$ Abertura da peneira imediatamente acima da escala $(\mathrm{cm})$. $\rho=$ Densidade da amostra a ser ensaiada $\left(\mathrm{g} / \mathrm{cm}^{3}\right)$.

$A=$ Área da malha da peneira $\left(\mathrm{cm}^{2}\right)$.

$n=$ Camadas de partículas.

Os ensaios de teor de umidade do minério e de sua respectiva densidade foram realizados em triplicata, sendo o primeiro realizado em estufa e o segundo pelo método de picnometria.

\section{RESULTADOS E DISCUSSÃO}

Os ensaios de fragmentação e cominuição mostraram melhor desempenho devido à execução do circuito com carga circulante. Os limites de especificação dos produtos estão de acordo com a Tabela 1 e servem como referência para avaliar a otimização do processo.

Assim, por meio do ensaio granulométrico realizado através do peneiramento a seco e do peneiramento a úmido chegouse a distribuição granulométrica da amostra do minério de ferro, conforme apresentado na Tabela 2. De modo que, em concordância com os cálculos da massa máxima retida em cada

Tabela 2: Distribuição granulométrica do minério de ferro

\begin{tabular}{|c|c|c|c|c|c|}
\hline $\begin{array}{l}\text { Abertura } \\
(\mathrm{mm})\end{array}$ & $\begin{array}{l}\text { Massa } \\
(\mathrm{g})\end{array}$ & $\begin{array}{l}\text { Massa Máxima } \\
\text { (g) }\end{array}$ & $\begin{array}{l}\text { Retido Simples } \\
\text { (\%) }\end{array}$ & $\begin{array}{l}\text { Retido Acumulado } \\
\text { (\%) }\end{array}$ & $\begin{array}{l}\text { Passante Acumulado } \\
\text { (\%) }\end{array}$ \\
\hline 4,75 & 19,5 & & 11,96 & 11,96 & 88,04 \\
\hline 3,50 & 54,1 & 1446,81 & 33,17 & 45,13 & 54,87 \\
\hline 2,40 & 19,1 & 1034,69 & 11,71 & 56,84 & 43,16 \\
\hline 1,18 & 30,5 & 627,82 & 18,70 & 75,54 & 24,46 \\
\hline 0,850 & 7,60 & 356,00 & 4,66 & 80,20 & 19,80 \\
\hline 0,600 & 5,40 & 254,29 & 3,31 & 83,51 & 16,49 \\
\hline 0,425 & 6,50 & 179,76 & 3,99 & 87,50 & 12,50 \\
\hline 0,300 & 5,80 & 127,14 & 3,56 & 91,05 & 8,95 \\
\hline 0,212 & 6,90 & 89,79 & 4,23 & 95,28 & 4,72 \\
\hline 0,180 & 3,70 & 68,75 & 2,27 & 97,55 & 2,45 \\
\hline 0,150 & 1,60 & 57,87 & 0,98 & 98,53 & 1,47 \\
\hline$-0,150$ & 2,40 & & 1,47 & 100,00 & 0,00 \\
\hline$\Sigma$ & 163,1 & & 100,00 & & \\
\hline $\begin{array}{l}\text { Abertura } \\
(\mathrm{mm})\end{array}$ & $\begin{array}{l}\text { Massa } \\
(\mathrm{g})\end{array}$ & $\begin{array}{l}\text { Massa Máxima } \\
\text { (g) }\end{array}$ & $\begin{array}{l}\text { Retido Simples } \\
\text { (\%) }\end{array}$ & $\begin{array}{l}\text { Retido Acumulado } \\
\text { (\%) }\end{array}$ & $\begin{array}{l}\text { Passante Acumulado } \\
\text { (\%) }\end{array}$ \\
\hline 0,150 & 2,90 & 57,87 & 3,07 & 3,07 & 96,93 \\
\hline 0,106 & 16,04 & 44,90 & 16,98 & 20,06 & 79,94 \\
\hline 0,075 & 17,88 & 31,92 & 18,93 & 38,99 & 61,01 \\
\hline 0,053 & 15,27 & 22,45 & 16,17 & 55,16 & 44,84 \\
\hline 0,045 & 3,38 & 17,19 & 3,58 & 58,74 & 41,26 \\
\hline 0,038 & 12,55 & 14,56 & 13,29 & 72,02 & 27,98 \\
\hline$-0,038$ & 26,42 & & 27,98 & 100,00 & 0,00 \\
\hline$\Sigma$ & 94,44 & & 100,00 & & \\
\hline \multicolumn{6}{|c|}{$\begin{array}{l}-0,150 \text { : material passante na peneira de } 0,150 \mathrm{~mm} \\
-0,038 \text { : material passante na peneira de } 0,038 \mathrm{~mm}\end{array}$} \\
\hline
\end{tabular}

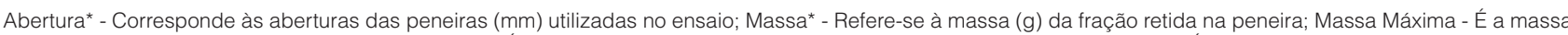
estimada pela fórmula de Gaudin(6); Retido Simples* ${ }^{*}$ É a percentagem retida numa determinada peneira; Retido Acumulado* - É a soma do percentual retido na peneira superior, com o percentual retido na peneira em estudo; Passante Acumulado* - Para seu cálculo inicia-se com a subtração do valor 100 pelo valor registrado na coluna Retido Acumulado. Registra-se a diferença na linha correspondente da coluna Passante Acumulado. Repete-se a operação até o último valor na coluna Passante Acumulado. ${ }^{*}$ Fonte: Sampaio, França e Braga( ${ }^{(7)}$ 
peneira (Fig. 2), foi possível verificar a validade do peneiramento e que, de modo geral, a amostra retida em cada peneira foi inferior ao máximo calculado pela fórmula de Gaudin ${ }^{(6)}$. Graficamente o d80 para a distribuição de sinter feed foi aproximadamente a 5,00 $\mathrm{mm}$, portanto, $80 \%$ da amostra encontrou-se abaixo de $5,00 \mathrm{~mm}$, já para a distribuição de pellet feed foi aproximadamente a $0,150 \mathrm{~mm}$, portanto, $80 \%$ da amostra encontrou-se abaixo de $0,150 \mathrm{~mm}$

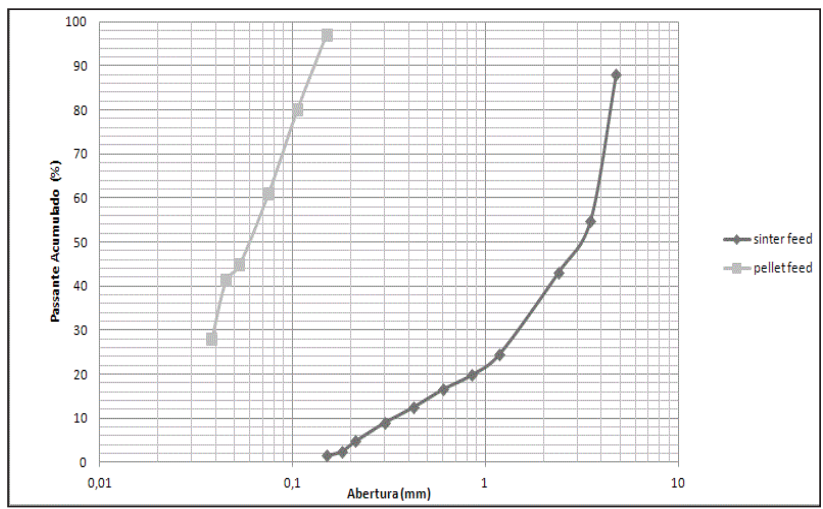

Figura 2: Distribuição granulométrica da amostra do minério de ferro - \% Passante acumulado

Assim, como descrito por Abelha ${ }^{(8)}$ é de extrema importância realizar a conferência de todo processo de classificação, bem como uma inspeção física dos principais componentes das peneiras, perdas de componentes, inspeção no minério utilizado e suas características como curva granulométrica, abrasividade, alimentação da peneira e top size do material. A necessidade de se promover uma visão mais ampla da eficiência dessa etapa não é somente voltada para sua otimização, engloba também os processos posteriores de concentração do minério.

A verificação realizada sobre a distribuição granulométrica de sinter feed e pellet feed apresentaram valores que atenderam a especificação discriminada na Tabela 1, sendo os resultados obtidos expressos na Tabela 3.

Tabela 3: Verificação da produção de pellet feed e sinter feed quanto à especificação

\begin{tabular}{|c|c|c|c|}
\hline Sinter Feed & $\%$ & Limite (\%) & Validado \\
\hline$+6,35 \mathrm{~mm}$ & 0 & 10 & SIM \\
\hline$-0,150 \mathrm{~mm}$ & 1,47 & 42 & SIM \\
\hline Pellet Feed & $\%$ & Limite $(\%)$ & Validado \\
\hline$+0,150 \mathrm{~mm}$ & 3,07 & 5 & SIM \\
\hline$-0,044 \mathrm{~mm}$ & 41,26 & 80 & SIM \\
\hline
\end{tabular}

Ademais, determinou-se que o teor de umidade do minério itabirítico foi de cerca de $0,81 \%$ e a densidade calculada foi de $3,61 \mathrm{~g} / \mathrm{cm}^{3}$.
De uma maneira geral, os estudos do perfil granulométrico deste minério exprimem e dão subsídio à necessidade de sua caracterização em todos os segmentos que cerceiam a sua produção, visando um maior aproveitamento deste tipo de minério $^{(9)}$.

\section{CONCLUSÕES}

A técnica de otimização do circuito em laboratório para produção de pellet feed e sinter feed quanto à granulometria mostra as vantagens em se restringir perdas e retrabalho em escala industrial.

O alto nível de controle nas etapas de peneiramento (tempo, velocidade de agitação, taxa de alimentação etc) e a definição dos parâmetros dos equipamentos são essenciais para garantir a qualidade da análise granulométrica do minério e assim, assegurar a sua especificação quanto à classificação granulométrica propiciando ao setor mineral e siderúrgico, uma maior recuperação e qualidade dos minérios itabiríticos.

\section{REFERENCES}

1. BENNETT, R. L., Characteristics of Iron Ore and Agglomeration as relates to Furnace Use - SME Mineral Processing Handbook, 1985.

2. QUARESMA, F. L., Balanço Mineral Brasileiro, 2001. DNPM Ministério de Minas e Energia, Brasil.

3. JESUS, C. A. G., Sumário Mineral, 2015. Ferro. DNPM - Ministério de Minas e Energia, Brasil.

4. FERREIRA, D. H. O., Principais Etapas do Tratamento de Minérios Itabiríticos do Quadrilátero Ferrífero. Universidade Federal de Minas Gerais. Belo Horizonte. 2011.

5. LIMA, R. M. F., Adsorção de amido e amina na superfície de hematita e do quartzo e sua influência na flotação. Belo Horizonte, 1997. Vol.1. 238p. Tese. (Curso de Pós-Graduação em Engenharia Metalúrgica e de Minas - Área de Concentração: Tecnologia Mineral)

6. GAUDIN, A. M., Principles of Mineral Dressing. New York: Mcgraw - Hill, 1975

7. SAMPAIO, J.A., SILVA, F.A.N.G., Análise granulométrica por peneiramento, In: SAMPAIO, J.A., FRANÇA,S.C.A., BRAGA,P.F.A (Ed.), Tratamento de Minérios: Práticas laboratoriais. CETEM/ MCT, 2007, p. 55-74.

8. ABELHA, D., Peneiramento de diferentes tipos de minérios utilizando o conceito "Pro-Deck". Revista HOLOS, Instituto Federal de Educação, Ciência e Tecnologia Rio Grande do Norte, v.1, n.32, p. 373-380, Janeiro, 2016. Disponível em: <http://www2.ifrn.edu.br/ojs/index.php/HOLOS/issue/view/100> Acesso em: 21 dez. 2016

9. LWAMBA, E., GARBERS-CRAIG, A.M., Control of the grain size distribution of the raw material mixture in the production of iron sinter. The Journal of The Southern African Institute of Mining and Metallurgy, Southern African, v. 106, p.293-299, May 2008. 